\title{
Selective Aspiration or Neurotoxic Lesions of Orbital Frontal Areas 11 and 13 Spared Monkeys' Performance on the Object Discrimination Reversal Task
}

\author{
Andy Kazama and Jocelyne Bachevalier \\ Department of Neurobiology and Anatomy, University of Texas Health Science Center, Houston, Texas 77030
}

\begin{abstract}
Damage to the orbital frontal cortex (OFC) has long been associated with reversal learning deficits in several species. In monkeys, this impairment follows lesions that include several OFC subfields. However, the different connectional patterns of OFC subfields together with neuroimaging data in humans have suggested that specific OFC areas play distinctive roles in processing information necessary to guide behavior (Kringelbach and Rolls, 2004; Barbas, 2007; Price, 2007). More specifically, areas 11 and 13 contribute to a sensory network, whereas medial areas 10,14, and 25 are heavily connected to a visceromotor network. To examine the contribution of areas 11 and 13 to reversal learning, we tested monkeys with selective damage to these two OFC areas on two versions of the ODR task using either one or five discrimination problems. We compared their performance with that of sham-operated controls and of animals with neurotoxic amygdala lesions, which served as operated controls. Neither damage to areas 11 and 13 nor damage to the amygdala affected performance on the ODR tasks. The results indicate that areas 11 and 13 do not critically contribute to reversal learning and that adjacent damage to OFC subfields $(10,12,14$, and 25) could account for the ODR deficits found in earlier lesion studies. This sparing of reversal learning will be discussed in relation to deficits found in the same animals on tasks that measure behavioral modulation when relative value of affective (positive and negative) stimuli was manipulated.
\end{abstract}

\section{Introduction}

Damage to the orbital frontal cortex (OFC) has long been associated with impairment in behavioral adaptation (Teitelbaum, 1964; Butter, 1969; Jones and Mishkin, 1972; Rolls et al., 1994; Dias et al., 1996; Bechara et al., 1997; Meunier et al., 1997; Ferry et al., 2000; Schoenbaum et al., 2002, 2003; Bohn et al., 2003; Chudasama and Robbins, 2003; Fellows and Farah, 2003; McAlonan and Brown, 2003; Hornak et al., 2004; Izquierdo et al., 2004; Kim and Ragozzino, 2005). This impairment is generally observed in the object discrimination reversal (ODR) task, in which subjects first respond to one of two cues to receive a reward and then inhibit responding to this rewarded cue upon reversal of the reward contingency. Following OFC damage, subjects typically learn the initial discrimination normally, but make more errors than controls on the reversals. For monkeys, the reversal deficit usually follows damage that encompasses several OFC subregions (Barbas and Pandya, 1989; Amaral et al., 1992; Carmichael and

Received Sept. 17, 2008; revised Jan. 13, 2009; accepted Jan. 22, 2009.

This work was supported by grants from the National Institute of Mental Health (MH-58846), the National Institute of Child Health and Human Development (HD-35471), Autism Speaks Mentor-Based Predoctoral Fellowship, Yerkes Base Grant NIH RR00165, and Center for Behavioral Neuroscience Grant NSF IBN-9876754. We thank the University of Texas Health Science Center at Houston veterinary and animal husbandry staff for expert animal care, Jairus O'Malley, Ernest Baskin, and Zachary Torrey for help with the behavioral testing of the animals, Roger E. Price and Belinda Rivera for the care and handling of animals during the MR imaging procedures, and Edward F. Jackson for assistance in neuroimaging techniques.

Correspondence should be addressed to Jocelyne Bachevalier at her present address: Yerkes National Primate Research Center, Emory University, 954 Gatewood Road, Atlanta, GA 30329. E-mail: jbachev@emory.edu.

A. Kazama's present address: Department of Psychology, Emory University, Atlanta, GA 30322.

D01:10.1523/JNEUROSCI.4655-08.2009

Copyright $\odot 2009$ Society for Neuroscience $\quad$ 0270-6474/09/292794-11\$15.00/0
Price, 1994), including the middle areas 11/13, rostral area 10, ventromedial areas 14/25, and, in some instances, lateral areas 12/47 (Iversen and Mishkin, 1970; Jones and Mishkin, 1972; Meunier et al., 1997; Izquierdo et al., 2004). The one exception is the earlier study of Butter (1969), who demonstrated severe reversal deficits after lesions restricted to area 12, but not after lesions of either the anteromedial areas 10/11 or the posteromedial areas 13 and insular area (ia), suggesting that not all OFC subfields are critical for reversal learning [see also Roberts (2006) and Wallis (2007)]. These results are in line with recent anatomical maps and connectional networks of OFC subfields (Petrides and Pandya, 1984; Carmichael and Price, 1994; Price et al., 1996; Barbas et al., 2005) indicating the presence of two distinct networks: an "orbital" network (areas 11/13 and ia), and a "medial" network (areas 14/10) with its extensive connections with area 12 laterally and areas 25/32 medially (Barbas, 2007; Price, 2007). Functional distinctions between different OFC subfields came also from recent neuroimaging studies (Elliott et al., 2000a,b; Kringelbach and Rolls, 2003; O'Doherty et al., 2003; Hurliman et al., 2005). In the present study, we assessed the effects of selective lesions to OFC areas 11/13 on ODR in monkeys. Since reversal deficits following OFC lesions could be associated with task difficulty (Kim and Ragozzino, 2005), we also used two ODR tasks differing in the number of discrimination problems, i.e., one versus five problems, to be learned and reversed. Finally, as an operated comparison group, monkeys with neurotoxic amygdala lesions were also tested on the two tasks since these lesions do not disrupt ODR performance (Izquierdo and Murray, 2007). Given 

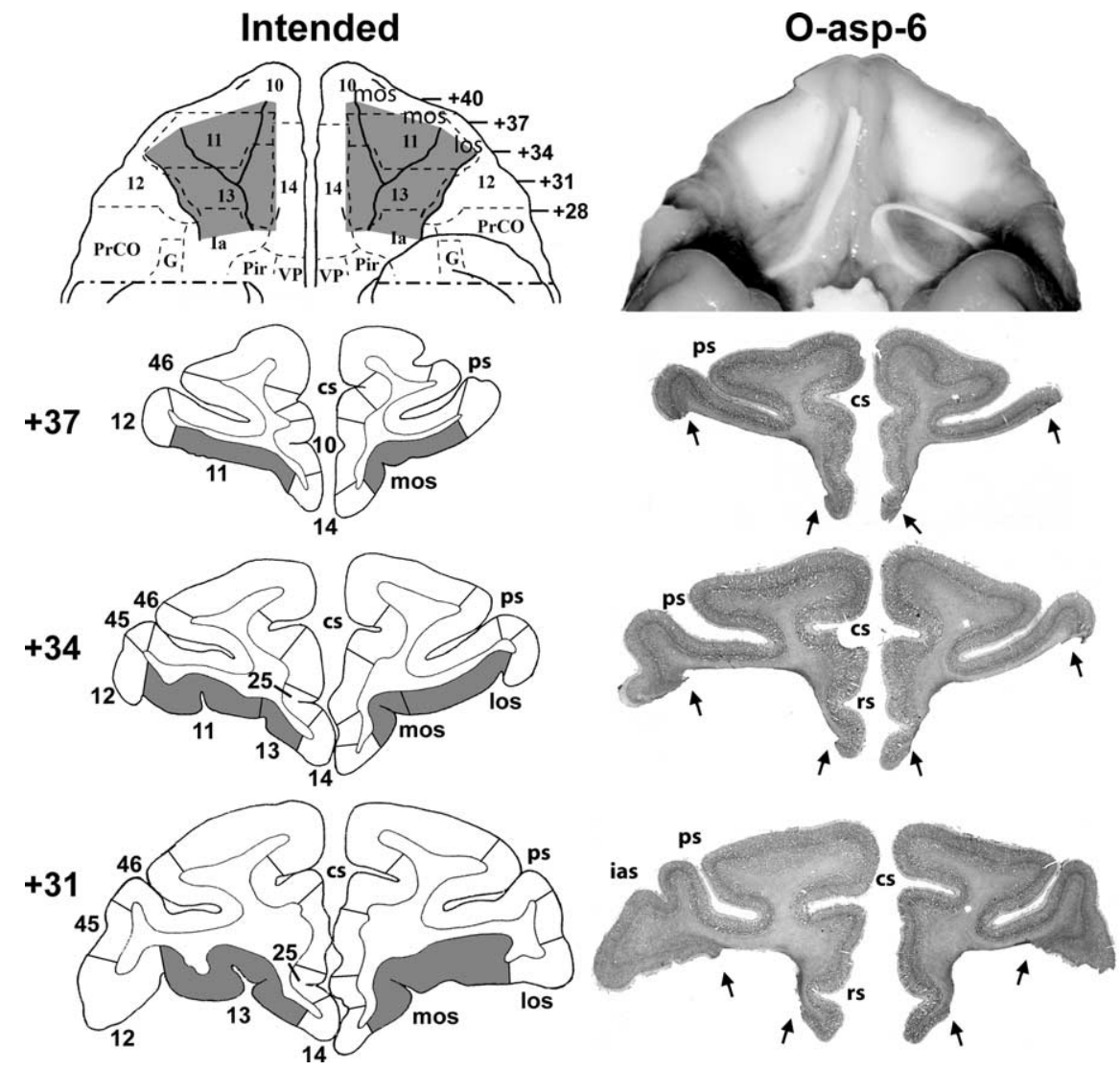

Figure 1. Ventral views and coronal sections through the orbital frontal cortex of a macaque brain. Left panels depict in gray the intended lesions to mainly target areas 11 and 13 as reconstructed onto a ventral view and three coronal levels. Right panels depict the extent of lesion for case 0 -asp-6 shown in a photograph of the orbital frontal surface (top) and revealing the exposed underlying white matter in the areas where the cortex was aspirated. Below are photographs of histological sections through the orbital frontal cortex at three coronal levels. The numerals on the left of the coronal sections indicate the distance in millimeters from the interaural plane. cs, Cingulate sulcus; G, gustatory cortex; la, insular (agranular); ias, inferior arcuate sulcus; los, lateral orbital sulcus; mos, medial orbital sulcus; Pir, piriform cortex; PrC0, precentral opercular area; ps, principal sulcus; rs, rostral sulcus; VP, ventral pallidum. Cytoarchitectonic fields are as described by Barbas and Pandya (1989), Amaral et al. (1992), and Carmichael and Price (1994).

the earlier findings of Butter (1969), we predicted that restricting the OFC damage to areas $11 / 13$ would spare reversal learning.

\section{Materials and Methods \\ Subjects}

Twenty adult male rhesus macaques (Macaca mulatta), $\sim 3.5$ years of age at time of surgery, were used. All animals were housed individually, maintained on a $12 \mathrm{~h}$ light/dark cycle, and fed Purina primate chow supplemented with fresh fruit. Water was given ad libitum. During the behavioral testing, daily food intake was minimally restricted to ensure that the animal remained motivated to retrieve food rewards. The animals were divided into three experimental groups. Group C consisted of four sham-operated controls and two unoperated controls. Groups $\mathrm{O}$-ibo and $\mathrm{O}$-asp included two animals with neurotoxic lesions and five animals with aspiration lesions of areas 11 and 13, and group A-ibo included seven animals with neurotoxic amygdala lesions. Before surgery, all animals received testing on social interactions, food preference, and emotional reactivity (intruder task). After surgery, they were given tests of novelty preference (visual-paired comparison task) and social interactions, and retrained on the food preference and intruder tasks. They were then tested on the devaluation reinforcer task, $\sim 12$ months after surgery and received the one-pair and five-pair ODR, $\sim 18$ months after surgery. The data obtained on social interactions, food preference, emotional reactivity (intruder task), and devaluation reinforcer task have previously been published (Machado and Bachevalier, 2006; 2007a and b).
All procedures were approved by the Animal Care and Use Committee of the University of Texas Health Science Center, Houston, and performed in accordance with the National Institute of Health Guide for the Care and Use of Laboratory Animals. Neuroimaging and surgical procedures have been previously described in detail (Nemanic et al., 2002, 2004; Machado and Bachevalier, 2006, 2007), and only a brief report will be given below.

\section{Magnetic resonance imaging}

MRI procedures were performed under anesthesia induced by ketamine hydrochloride (10 $\mathrm{mg} / \mathrm{kg}$, i.m.) followed by isoflurane gas (1.0 $2.0 \%, \mathrm{v} / \mathrm{v}$, to effect). The animal's head was secured into a nonferromagnetic stereotaxic apparatus (Crist Instrument), centered within the scanner bore (GE Signa 1.5 Tesla Echo Speed scanner, GE Medical Systems), and imaged with a 5" surface coil. Two MRI sessions (1-3 weeks before surgery and 7-10 d after surgery) were given to all animals except those in group C. During each session, two series of coronal images were taken through the entire brain: a T1-weighted structural (1 $\mathrm{mm}$ in thickness) and three Fluid Attenuated Inversion Recovery (FLAIR, $3 \mathrm{~mm}$ thick, each offset by $1 \mathrm{~mm}$ ) scans. The presurgical T1-weighted images were used either to derive the stereotaxic coordinates for each injection site (Saunders et al., 1990) for animals in group A-ibo or to localize the orbital frontal sulci and determine the extent of orbital frontal areas 11 and 13 in animals of groups O-ibo and O-asp (Machado and Bachevalier, 2006, 2007a,b). Postsurgical FLAIR images were compared with matched presurgical FLAIR and T1-weighted images to accurately identify localized areas of edema indicative of neurotoxin-induced cell death, and were therefore used to quantify the extent of lesion for all animals in groups $\mathrm{A}$-ibo and $\mathrm{O}$-ibo (Málková et al., 2001; Nemanic et al., 2002). Postsurgical T1-weighted images were compared with matched presurgical T1-weighted images to identify the location and quantify the extent of orbital frontal cortex aspiration lesions (group O-asp).

\section{Surgical procedures}

All surgical procedures were performed under aseptic conditions, and anesthesia was induced by ketamine hydrochloride $(10 \mathrm{mg} / \mathrm{kg}, \mathrm{i} . \mathrm{m}$.) followed by isoflurane gas $(1.0-2.0 \%, \mathrm{v} / \mathrm{v}$, to effect). An intravenous drip of $0.45 \%$ sodium chloride was used for hydration, vital signs were continuously monitored, and a heating pad placed under the animal prevented hypothermia. Animals in group A-ibo were repositioned into the stereotaxic apparatus, whereas those in groups $\mathrm{O}$-ibo and $\mathrm{O}$-asp had their head secured into a head holder, which permitted free rotation of the animal's head during surgery. The animal's head was then shaved and disinfected with Nolvasan solution, and a local anesthetic (Marcaine, 25\%, $1.5 \mathrm{M}$, s.c.) was injected under the skin along the incision line. The skin and connective tissue were incised and gently retracted together with the temporalis muscles. Each group then underwent lesion-specific procedures.

Orbital frontal cortex lesion. Orbital frontal cortex lesions (both ibotenic and aspiration) were intended to damage the middle sector of the orbital frontal surface, including areas 11 and 13 (Barbas and Pandya, 1989; Amaral et al., 1992; Carmichael and Price, 1994). Given the individual variations in the shape and length of the orbital sulci, presurgical T1-weighted MR images were used to reconstruct the ventral surface of the frontal lobe for each animal. The boundaries of areas 11 and 13 on the 
ventral surface of the frontal lobe were defined as (1) a line joining the anterior tips of the medial and lateral orbital sulci, anteriorly, (2) a line joining the medial bank of the lateral orbital sulcus to the olfactory stria just anterior to its division into the medial and lateral olfactory tracts, posteriorly, (3) the medial border of the olfactory stria, medially, and (4) the medial bank of the lateral orbital sulcus from its anterior tip to the posterior border of the lesion, laterally. These borders approximate the extent of areas 11 and 13 in the macaque monkey (Fig. 1, left panels).

The bone of the supraorbital ridge was opened and eroded, the dura was cut and retracted, and the brain was gently elevated to gain a full view of the orbital frontal surface. With the aid of a surgical microscope, the lateral and medial orbital sulci and the olfactory stria were visualized. For the neurotoxin injections, $17-36$ injection sites were equally spaced $(\sim 2$ $\mathrm{mm}$ apart in the lateral/medial and anterior/posterior planes) within these borders. A 30 gauge needle attached to a $10 \mu \mathrm{l}$ Hamilton syringe by polyethylene tubing was used to manually inject $0.4-0.8 \mu \mathrm{l}$ of ibotenic acid $(0.4 \mu \mathrm{l} / \mathrm{min})$ at each site. For the aspiration lesions (Meunier et al., 1997), 21 and 23 gauge aspirating probes in combination with electrocautery was used to gently aspirate the cortical layers until the white matter beneath the cortical mantle could be seen.

Neurotoxic amygdala lesion. Using the presurgical T1-weighted MR images, the coordinates of 15 injection sites were selected within the amygdala to damage all amygdaloid nuclei. Two small craniotomies were performed to expose the brain just above the injection sites and small slits in the dura permitted the needle of a $10 \mu \mathrm{l}$ Hamilton syringe, held by a Kopf electrode manipulator (David Kopf Instruments), to be lowered to the appropriate injection coordinates. Two Hamilton syringes were filled with ibotenic acid (Biosearch Technologies, $10 \mathrm{mg} / \mathrm{ml}$ in PBS, pH 7.4) and used to inject $0.2-0.6 \mu \mathrm{l}$ of ibotenic acid to each site at a rate of 0.4 $\mu \mathrm{l} / \mathrm{min}$. To reduce intracranial swelling, Mannitol $(20 \%, 1 \mathrm{ml} / \mathrm{min}$, i.v.) was given just before the end of the surgical procedure.

Sham lesions. For sham lesions, bilateral craniotomies (similar to those used for amygdala lesions) were made as described above. The dura was cut but no needle penetrations occurred.

Following the specific surgical procedure of each type of lesions, tissues were closed in anatomical layers, and the animal was removed from isoflurane gas and recovered in the surgical facility until it could breathe on its own and maintained an $\mathrm{SPO}_{2}$ of $>88 \%$ for $1 \mathrm{~h}$. Beginning $12 \mathrm{~h}$ before surgery and continuing until 1 week after surgery, all animals were treated with dexamethasone sodium phosphate $(0.4 \mathrm{mg} / \mathrm{kg}$, i.m.) and Cephazolin $(25 \mathrm{mg} / \mathrm{kg}$, i.m.) to prevent excessive immunoreactivity and protect against infection, respectively. For $3 \mathrm{~d}$ following surgery, animals also received an analgesic (acetaminophen, $10 \mathrm{mg} / \mathrm{kg}$, p.o.) to minimize pain. All animals were given a $7 \mathrm{~d}$ postsurgical regimen of dexamethasone sodium phosphate $(0.4 \mathrm{mg} / \mathrm{kg}$ i.m.) to reduce swelling, Cefazolin (25 $\mathrm{mg} / \mathrm{kg}$ i.m.) to minimize infection, and acetaminophen (10 mg/kg, p.o.) for postoperative pain management.

\section{Lesion assessment}

Because eight animals (cases O-ibo-1 and -2, cases O-asp-1 and -2, and cases A-ibo-1 to -4) died in the flooding of Tropical Storm Allison in June 2001 , the extent of lesion in those cases was determined using the presurgical and postsurgical scans (Málková et al., 2001; Nemanic et al., 2002). Histology is available only for the six remaining animals (cases O-asp-4 to -6 and cases A-ibo- 6 to -8 ) that were added to the study after the storm.

MRI lesion assessment. For all animals in groups $\mathrm{A}$-ibo and $\mathrm{O}-\mathrm{ibo}$, presurgical T1-weighted $1 \mathrm{~mm}$ coronal images and presurgical and postsurgical FLAIR $1 \mathrm{~mm}$ coronal images were matched with drawings of coronal sections from a normalized rhesus monkey template brain at 1 $\mathrm{mm}$ intervals. Hypersignals identified on FLAIR MR images were plotted onto corresponding drawings from the template brain, which were then imported into a Java-based image analysis program (ImageJ; http:// rsb.info.nih.gov/ij/) to measure the surface area (in pixels squared) of damage for intended targets, as well as all adjacent areas that may have sustained inadvertent damage. For any given region of interest (ROI), the surface area of hypersignals on each section through each hemisphere was summed and then multiplied by image thickness $(1 \mathrm{~mm})$ to calculate a total volume of damage (Gundersen and Jensen, 1987). For each ROI, the volume of damage for each hemisphere was then divided by the
Table 1. Extent of intended and unintended damage in group 0 in areas 10-13

\begin{tabular}{|c|c|c|c|c|c|c|c|c|c|c|c|c|}
\hline \multirow[b]{2}{*}{ Cases } & \multicolumn{4}{|c|}{ Areas 11 and 13} & \multicolumn{4}{|c|}{ Area 10} & \multicolumn{4}{|c|}{ Area 12} \\
\hline & L & $\mathrm{R}$ & Avg & W & L & R & Avg & W & L & R & Avg & W \\
\hline & 36.3 & & & 10.8 & & & 4.6 & 0.2 & 2.3 & 3.7 & 3.0 & 0.1 \\
\hline & 33.9 & 37 & 6 & & 0 & 0 & 0 & 0 & & 2 & .4 & 0.03 \\
\hline 1 & 88.4 & 95.3 & 91.8 & 84.2 & 14.8 & 7.2 & 11.4 & 1.2 & .9 & 28.9 & 16.4 & 1.1 \\
\hline 2 & 83.0 & 91.9 & 87.5 & 76.3 & 5.6 & 9 & 3 & 0.3 & 7 & 9.3 & 8.2 & 0.7 \\
\hline 4 & 86.8 & 85.9 & 86.3 & 74.5 & 7.3 & 6.2 & 6.7 & 0.5 & 21.5 & 30.1 & 25.8 & 6.5 \\
\hline & 82.5 & 84.1 & 83.3 & 69.4 & 8.1 & 16.5 & 12.3 & 1.3 & 17.5 & 25.6 & 21.5 & 4.5 \\
\hline 0 -asp-6 6 & 94.4 & 97.4 & 95.9 & 92.0 & 3.4 & 6.1 & 4.7 & 0.2 & 7.7 & 16.5 & 12.1 & 1.3 \\
\hline & 72.2 & 74.6 & 73.4 & 60.0 & 6.3 & 6.5 & 6.4 & 0.5 & 8.6 & 17.2 & 12.9 & 2.0 \\
\hline
\end{tabular}

Data are the estimated percentage of damage as assessed from MR (postsurgical FLAIR and T1) images. L, Percentage of damage to the left hemisphere; $R$, percentage of damage to the right hemisphere; Avg, average of $L$ and $R$; $W=(L \times R) / 100$ [weighted index as defined by Hodos and Bobko (1984)]; $X$, group mean. Areas 10,11, 12, and 13, Cytoarchitectonic subregions of the macaque frontal lobe as defined by Carmichael and Price (1994).

Table 2. Extent of unintended damage in group 0 in areas 14, la, and 46

\begin{tabular}{|c|c|c|c|c|c|c|c|c|c|c|c|c|}
\hline \multirow[b]{2}{*}{ Cases } & \multicolumn{4}{|c|}{ Area 14} & \multicolumn{4}{|l|}{ la } & \multicolumn{4}{|c|}{ Area 46} \\
\hline & L & $\mathrm{R}$ & Avg & W & $\mathrm{L}$ & $\mathrm{R}$ & Avg & W & $\mathrm{L}$ & $\mathrm{R}$ & Avg & W \\
\hline 0-ibo-1 & 49.0 & 23.8 & 36.4 & 11.7 & 37.0 & 25.3 & 31.2 & 9.4 & 0 & 0 & 0 & 0 \\
\hline 0 -ibo-2 & 8.3 & 5.9 & 7.1 & 0.5 & 28.2 & 34.3 & 31.3 & 9.6 & 0 & 3.3 & 1.7 & 0 \\
\hline 0 -asp-1 & 15.2 & 21.7 & 18.5 & 3.3 & 20.6 & 21.1 & 20.9 & 4.3 & 0 & 0 & 0 & 0 \\
\hline 0 -asp-2 & 10.7 & 5.9 & 8.3 & 0.6 & 21.4 & 23.7 & 22.6 & 5.1 & 0 & 0 & 0 & 0 \\
\hline 0 -asp-4 & 0.9 & 1.2 & 1.1 & 0 & 37.5 & 28.3 & 32.9 & 10.6 & 0 & 0.3 & 0.1 & 0 \\
\hline 0 -asp-5 & 0.7 & 1.4 & 1.0 & 0 & 12.2 & 9.8 & 11.0 & 1.2 & 0.9 & 0.8 & 0.9 & 0.01 \\
\hline 0 -asp-6 & 6.6 & 7.9 & 7.3 & 0.5 & 8.8 & 7.7 & 8.3 & 0.7 & 0 & 0 & 0 & 0 \\
\hline$X$ & 13.1 & 9.7 & 11.4 & 2.4 & 23.7 & 21.5 & 22.6 & 5.8 & 0.1 & 0.6 & 0.4 & 0.001 \\
\hline
\end{tabular}

Data are the estimated percentage of damage as assessed from MR (postsurgical FLAIR and T1) images. Abbreviations are as in Table 1. Areas 14 and 46, Cytoarchitectonic subregions of the macaque frontal lobe; la, agranular insular areas as defined by Carmichael and Price (1994).

volume of that ROI in the normal brain to indicate a percentage of the total volume damaged.

For animals in group $\mathrm{O}$-asp, presurgical and postsurgical T1-weighted $1 \mathrm{~mm}$ coronal images were matched to corresponding drawings from the normalized rhesus monkey template brain. The extent of orbital frontal tissue damaged found on all postsurgery $\mathrm{T} 1$-weighted images were drawn onto the corresponding drawings of the normal brain and extent of tissue aspirated from the orbital frontal areas 11 and 13, as well as inadvertent damage to adjacent cortical areas 10, 12, 14, 25, and ia were measured as described above for the MR investigation.

Histology lesion assessment. At completion of behavioral testing, the six animals were sedated (ketamine hydrochloride, $10 \mathrm{mg} / \mathrm{kg}$, i.m.), given a lethal dose of sodium pentobarbital, and perfused intracardially with $0.9 \%$ saline followed by $4.0 \%$ paraformaldehyde. The brain was photographed and cut frozen at $50 \mu \mathrm{m}$ in the coronal plane. Every fifth section was mounted and stained with thionin to visualize cell bodies, and every 20th section was mounted and impregnated with silver (Gallyas, 1979) to visualize fibers. Histological sections were microscopically examined to evaluate the extent of cell loss, gliosis, and fiber damage. Percentage of damage to intended areas and inadvertent damage to adjacent areas was calculated as above by plotting the damage seen on each histological section onto a matched digital drawing of a coronal section from the template brain. For all cases that received both MR and histological investigation of the lesion extent, results obtained for each monkey with both procedures were then compared (Pearson's moment correlation).

\section{Behavioral testing}

Apparatus and stimuli. Animals were trained in a Wisconsin General Testing Apparatus (WGTA) located in a darkened room containing a white noise generator to mask external sounds. The WGTA was equipped with a tray containing three food wells $(2 \mathrm{~cm}$ in diameter, $1 \mathrm{~cm}$ deep, and $13 \mathrm{~cm}$ apart center to center). Only the two lateral wells were used to hide food rewards, i.e., M\&M (Mars) or raisin (Sun-Maid Growers of California), under three-dimensional junk objects varying in color, shape, and texture.

Single-pair object discrimination reversal task. In this task (Jones and Mishkin, 1972), two objects formed a single discrimination problem. 
Table 3. Extent of intended and unintended damage in group A-ibo

\begin{tabular}{|c|c|c|c|c|c|c|c|c|}
\hline \multirow[b]{2}{*}{ Cases } & \multicolumn{4}{|c|}{ Amygdala } & \multicolumn{4}{|c|}{ Hippocampal formation } \\
\hline & $\mathrm{L}$ & $\mathrm{R}$ & Avg & W & $\mathrm{L}$ & $\mathrm{R}$ & Avg & W \\
\hline A-ibo-1 & 20.6 & 82.2 & 51.4 & 17 & 10.6 & 1.6 & 6.1 & 0.2 \\
\hline A-ibo-2 & 48.9 & 88.1 & 68.5 & 43.1 & 1.2 & 0 & 0.6 & 0 \\
\hline A-ibo-3 & 27.1 & 73.1 & 50.1 & 19.8 & 15.7 & 13.6 & 14.6 & 2.1 \\
\hline A-ibo-4 & 79.1 & 92.5 & 85.8 & 73.2 & 3.4 & 3 & 3.2 & 0.1 \\
\hline A-ibo-7 & 80.8 & 96.4 & 88.6 & 77.9 & 5.4 & 3.6 & 4.5 & 0.2 \\
\hline A-ibo-8 & 29.6 & 44.3 & 36.9 & 13.1 & 0 & 0 & 0 & 0 \\
\hline A-ibo-9 & 43.9 & 75.2 & 59.6 & 33.0 & 0 & 0 & 0 & 0 \\
\hline$x$ & 47.1 & 78.8 & 62.9 & 39.6 & 5.2 & 3.1 & 4.1 & 0.4 \\
\hline
\end{tabular}

Data are the estimated percentage of damage as assessed from MR (postsurgical T2 FLAIR) images. Abbreviations are as in Table 1.
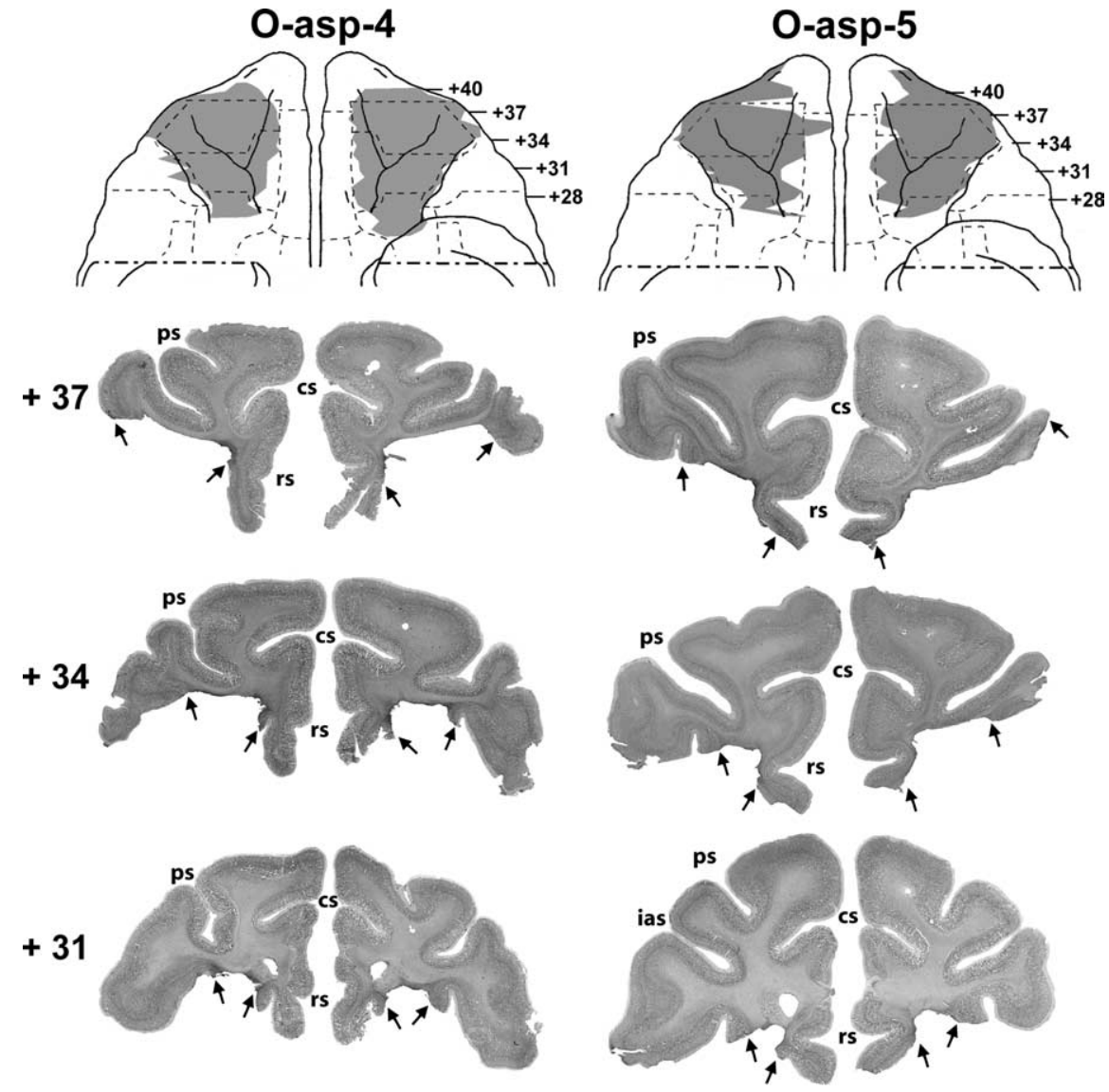

Figure 2. Ventral views of the orbital frontal surface of the monkey brain (top row) depicting the extent of cortical damage in two cases with aspiration lesions (cases 0 -asp-4 and -5) as estimated from histological sections. Below are photomicrographs of histological sections through the orbital frontal cortex at three anterior-posterior levels. Arrows point to the extent of the lesion at each level. Conventions are as in Figure 1.

Animals had first to learn which of the two objects was associated with the food reward (acquisition phase) followed by six reversals. During the first trial of the acquisition phase, both objects covered a food reward and the object selected by the animal became the rewarded object $\left(\mathrm{S}^{+}\right)$for the remaining trials of the phase. Left/right positions of the $\mathrm{S}^{+}$varied according to a pseudorandom sequence (Gellerman, 1933). Animals were given a total of 30 trials per day at $5 \mathrm{~s}$ intertrial intervals until they reached a criterion of 28 correct choices over 30 trials $(>90 \%)$ on one day followed by a criterion of 24 correct choices in 30 trials $(>80 \%)$ on the next day. Upon reaching this criterion, the reward contingency was switched so that the $\mathrm{S}^{+}$became $\mathrm{S}^{-}$and vice versa. The animal was again given 30 trials per day until the same criterion was met, after which the reward contingency was switched again. The animals were given a total of six reversals. During acquisition phase and reversals, incorrect choices were corrected by rerunning the erroneous trial with the $\mathrm{S}^{+}$covering the reward and the $\mathrm{S}^{-}$placed beside the empty well. This correction was repeated as many times as necessary until the animals displaced the $\mathrm{S}^{+}$. The number of times the correction trial was repeated provided a measure of perseverative errors (Jones and Mishkin, 1972; Meunier et al., 1997).

Five-pair object discrimination reversal task. Only a subset of animals in each group (cases C-4 to -7 ; A-ibo-7 to -9 ; O-asp-4 to -6 ) were given a more difficult version of the ODR task, consisting of five concurrent discrimination problems. Ten novel objects were selected to form five pairs with only one object serving as the $\mathrm{S}^{+}$in each pair. Again, the $\mathrm{S}^{+}$for each pair was selected on the first five trials when both objects of the pairs covered a reward. A total of 40 trials were given per day so that each pair was repeated eight times within a daily session in a pseudorandom order. Similar to the one-pair ODR, the five-pair ODR consisted of an acquisition phase followed by six reversals. Criterion was set at 37 correct choices in 40 trials (>90\%) in one day followed by 34 correct choices in 40 trials $(>85 \%)$ in the next day.

Data analysis

For both tasks, performance scores for the acquisition phase included (1) total number of trials given and (2) total number of errors made before reaching criterion performance. For each reversal and for six reversals combined, performance scores included (1) reversal errors as defined as errors committed in the first attempt of each trial and (2) perseverative errors, as defined as the number of times a trial was repeated before the animal selected the positive object during the correction procedure. Thus, scores for reversal errors and perseverative errors did not overlap.

First, for the one-pair ODR, we determined whether the type of orbital frontal lesions differently affected performance on the task, scores of group O-ibo were compared with those of group O-asp using Student's $t$ tests (SPSS v. 15). No differences between the two orbital frontal lesion techniques were detected for trials to criterion in the acquisition phase, reversal errors, and perseverative errors (onetailed $t=0.576, \mathrm{df}=5, p=0.59 ; t=0.89, \mathrm{df}=$ $5, p=0.44$; and $t=0.73, \mathrm{df}=5, p=0.49$, respectively). Therefore, for group comparisons, these two groups were combined into a single group designated group O in Results. Despite the similar effect of the two types of lesions, statistical analysis excluding the two cases with neurotoxic lesions that demonstrated sparing of some of the OFC fields 11 and 13 (see Tables 1 and 2 and Fig. 4) were also reported.

For both tasks, one-way ANOVAs were used for group comparisons on trials and errors in the acquisition phase and on the total number of reversal errors and perseverative errors obtained across the six reversals, using one-tailed tests. General linear model repeated-measures ANOVAs (SPSS v. 15) with group (3) and reversals (6) were used to compare performance across the six reversals. A Huynh-Feldt correction was used to adjust the degrees of freedom if sphericity could not be assumed. Significant main effects of group were investigated further using onesided Dunnett's tests to investigate differences between group $\mathrm{C}$ and the two operated groups and Tukey tests when comparing the two operated groups to each other. Significant main effects of Phase were subjected to 
post hoc Bonferroni tests and significant interactions between Group and Phase were investigated with one-tailed paired-sample $t$ tests.

In addition to the aforementioned behavioral measures, we also conducted a general linear model repeated-measures ANOVA analysis of the distribution of errors according to the "stages of learning" previously proposed by Jones and Mishkin (1972). Briefly, these three stages are meant to assess potential group differences in learning patterns. Each stage is calculated by summing the cumulative correct responses per stage over the six reversals (not including the correction trials). Stage I is characterized by scores of 9 or fewer correct responses out of 30 trials, and represents the learning stage at which previous stimulusreward associations must be suppressed. Stage II is characterized by scores between 10 and 20 correct responses out of 30 trials, and represents the period when the animal is performing at or around chance level. Finally, stage III is characterized by scores between 21 and 30 correct choices out of 30 trials, and represents the learning period in which the subject consistently associates the stimulus with the reward at a near criterion level.

To compare performance between the two tasks, multivariate repeated-measures ANOVAs (groups $\times$ reversals $\times$ tasks) were performed. We also conducted Pearson product moment correlation matrices (SPSS v. 15) to compare extent of lesion for groups A-ibo, $\mathrm{O}$-ibo, and $\mathrm{O}$-asp with reversal errors and perseverative errors. All unintended damage to surrounding areas $>5 \%$ per area was included in the analysis.

\section{Results}

\section{Lesion extent}

The extent of lesion based on MR images has been described in detail in previous reports (Machado and Bachevalier, 2006, 2007a,b, 2008). Tables 1-3 summarize the extent of intended and unintended damage for each animal of group $\mathrm{O}$ and group $\mathrm{A}$-ibo, respectively. The weighted average $(W)$ (Hodos and Bobko, 1984) was calculated to determine whether damage was highly unilateral $(W \%<25 \%)$ or particularly extensive and bilaterally symmetrical $(W \%>50 \%)$. Histological sections were available for three cases in each group (cases O-asp-4 to -6 and A-ibo-7 to -9) and comparisons between neuroimaging and histological estimation of lesion were performed for these six cases. These correlations were very high for both groups A-ibo and O-asp (Pearson, $r=0.935$ and 0.910 , respectively).

For group $\mathrm{O}$, the aspiration lesions resulted in damage largely confined to areas 11 and 13, ranging from 83.3 to $95.9 \%$ as estimated from MRI (Tables 1, 2) and resulting in 78-94\% cell loss from histological material on cases O-asp-4 to -6. Figures 1 (right panels) and 2 illustrate the extent of OFC lesion on the ventral view of the brain and on histological coronal sections for these three cases. Reconstructions of the OFC aspiration lesions on the ventral view of the brain and T1 MR images at three anteriorposterior levels for the remaining two cases are shown in Figure 3. In contrast, the two cases with neurotoxic OFC lesions received incomplete damage to areas 11 and 13 (range: 33.3-35.6\%). Hypersignals were mostly confined to the superficial cortical layers and avoided the deepest layers, resulting in comparably lower total volume, but approximately the same extent of surface area damaged relative to group $\mathrm{O}$-asp. Unintended damage for all cases (Tables 1, 2, Fig. 4) included area 10 (range: $0-12.3 \%$ ), area 12 (range: $3.0-25.8 \%$ ), area 14 (range: $1.0-36.4 \%$ ), and ia (range: $8.3-32.9 \%)$.

For group A-ibo, the lesions resulted in damage largely confined to the amygdaloid nuclei, ranging from 36.9 to $88.6 \%$ as estimated from MRI (Table 3) and resulting in $27-73 \%$ cell loss from histological material in cases A-ibo-7 to -9 . MR images (FLAIR) through the amygdala lesions are provided for two representative cases in Figure 5. In addition, histological sections through the amygdala lesions of case A-ibo-8, which received the smallest lesion of the group, are presented in Figure 6. Sparing in this case was limited to the ventrolateral portion of the amygdala. Unintended damage for all cases was mild and limited almost exclusively to the anterior hippocampus (average: 4\%) (Table 3, Fig. 5, level +15).

\section{One-pair ODR}

The scores that each monkey obtained in the acquisition phase and six reversals are provided in Table 4 and illustrated in Figure 7.

Although two animals in group $\mathrm{O}$ and $\mathrm{A}$-ibo required more trials than animals in group $\mathrm{C}$ to acquire the discrimination problem (Table 4$)$, these differences did not reach significance $\left(F_{(2,17)}\right.$ $=0.79, p>0.05$ and $F_{(2,17)}=0.98, p>0.05$, for trials and errors, respectively). 
0-ibo-1
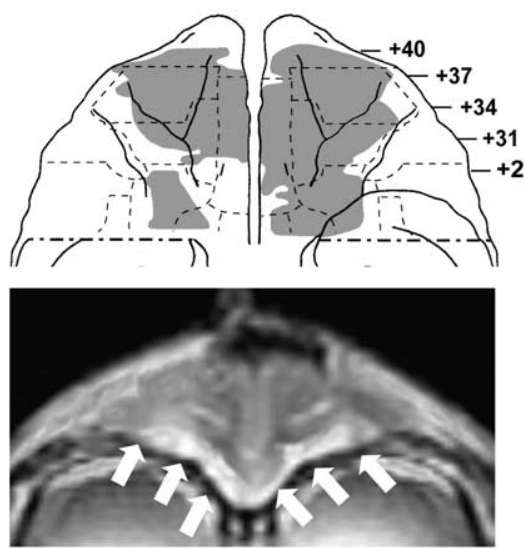

$+37$

$+34$

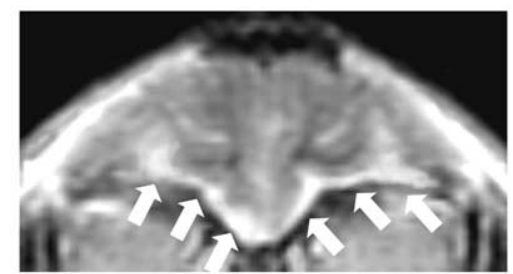

$+31$

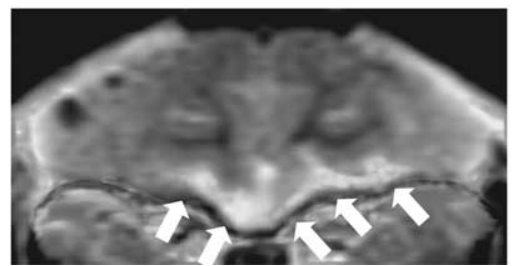

0-ibo-2
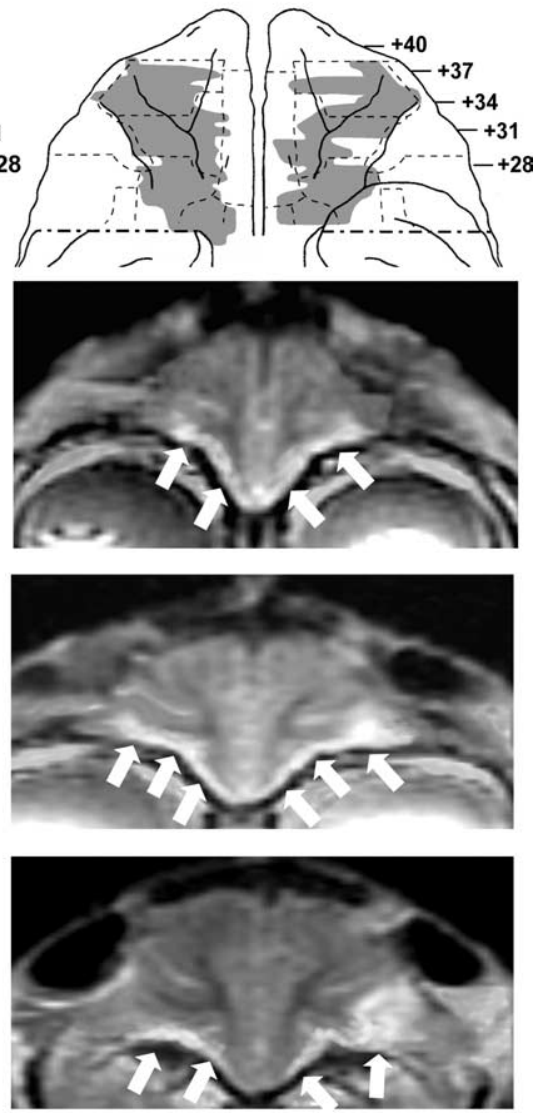

Figure 4. Ventral views of the orbital surface of the monkey brain (top row) depicting the extent of cortical damage in two cases with neurotoxic lesions (cases 0 -ibo- 1 and 0 -ibo-2) as estimated from postsurgical FLAIR MR images. Below are MR images through the orbital frontal cortex at three anterior-posterior levels. White arrows point to areas of hypersignals on the orbital frontal cortex. Note that hypersignals were more intense in the superficial layers than in the deep layers of the cortex. Conventions are as in Figure 1.

Similarly, the three groups performed equally well across the six reversals as revealed by a nonsignificant group effect $\left(F_{(2,17)}=\right.$ $2.72, p>0.05$ and $F_{(2,17)}=0.96, p>0.05$, for reversal errors and perseverative errors, respectively). The reversal factor was significant for perseverative errors (reversal effect: $F_{\text {Huynh-Feldt }(1.16,17)}=$ $4.22, p<0.05$ ), but not for reversal errors (reversal effect: $F_{(5,17)}$ $=0.98, p>0.05)$. Post hoc analyses revealed that all animals made slightly, but significantly, more perseverative errors in reversal 1 compared with reversal 6 (one-tailed $t=2.2, p=0.040$ ). No other contrasts were significant, and the interaction between groups and reversals did not reach significance. The same findings were obtained when the two cases with neurotoxic OFC lesions were removed from the analyses (group effect: $F_{(2,15)}=$ $3.13, p>0.05$ for reversal errors and $F_{(2,15)}=1.56, p>0.05$ for perseverative errors; reversal effect: $F_{(1.17,17.6)}=5.94, p<0.05$ for perseverative errors only). No other comparisons or interactions were significant.

Additionally, although number of total errors across the six reversals was slightly worse in groups $\mathrm{O}$ and $\mathrm{A}$-ibo compared with group C (see Table 4), these differences did not reach significance for reversal errors or perseverative errors when cases with neurotoxic lesions were included $\left(F_{(2,17)}=2.72, p>0.05\right.$ and $F_{(2,17)}=$ $0.96, p>0.05$, respectively) or excluded $\left(F_{(2,15)}=3.13, p>0.05\right.$ and $F_{(2,15)}=1.56, p>0.05$, respectively) from the analyses. It is interesting to note that two animals in group $\mathrm{O}$ (cases $\mathrm{O}$-asp-5 and
-6) made more perseverative errors than all other animals. These errors were made exclusively on the first two trials of the first reversal. Thus, case O-asp-5 made 89 perseverative errors on the first trial and few errors thereafter, and case O-asp-6 made 82, 175, and 11 perseverative errors in trials $1-3$. However, a comparison of the number of perseverative errors made in the first day of reversal 1 showed again no group differences $\left(F_{(2,17)}=0.54, p>0.05\right)$.

For stages of learning (Fig. 7), animals in the three groups did not differ $\left(F_{(2,17)}=1.06\right.$, $p>0.05)$, although the effect of stage was significant $\left(F_{(2,17)}=36.25, p<0.001\right)$. Thus, all groups made more errors during stage II, compared with stage I and stage III $\left(F_{(1,17)}=\right.$ 88.02, $p<0.05$ and $F_{(1,17)}=4.27, p<0.05$, respectively).

Finally, comparisons between scores on the task and percentage damage to adjacent cortical areas for group $\mathrm{O}$, revealed a positive correlation between the amount of damage to area 14 and reversal errors made on the first reversal $(r=0.78, p<$ $0.05)$ but not with perseverative errors. This correlation was not significant when the two cases with neurotoxic OFC lesions were removed from the analyses (Tables 1, 2, Fig. 4).

\section{Five-pair ODR}

As shown in Table 5 and Figure 7, the three groups learned the five-pair ODR at the same rate (group effect: $F_{(2,9)}=0.40, p>$ 0.05 and $F_{(2,9)}=0.11, p>0.05$, for trials and errors, respectively). Similarly, they performed equally well across the six reversals (group effect: $F_{(2,9)}=0.75, p>0.05$ and $F_{(2,9)}=0.93, p>$ 0.05 ; reversal effects: $F_{(5,9)}=2.90, p>0.05$ and $F_{(5,9)}=1.64, p>$ 0.05 ; group $\times$ reversal: $F_{(5,35)}=0.84, p>0.05$ and $F_{(5,35)}=0.98$, $p>0.05$, for reversal errors and perseverative errors, respectively). Overall performance across the six reversals was also comparable for the three groups $\left(F_{(2,9)}=2.72, p>0.05\right.$ and $F_{(2,9)}=$ $0.96, p>0.05$, for reversal errors and perseverative errors, respectively).

Furthermore, like for the one-pair ODR task, mean errors in the different stages of learning were similar for all groups $\left(F_{(2,10)}\right.$ $=0.74, p>0.05)$, but differed between stages for all groups $\left(F_{(2,10)}=8.67, p<0.01\right)$. Thus, all animals made more errors during stage II, than during stage I and stage III $\left(F_{(1,10)}=14.51\right.$, $p<0.01$ and $F_{(1,10)}=14.08, p<0.01$, respectively) (Fig. 7).

Because only three animals in each group were tested on the five-pair ODR task, the sample size did not provide enough statistical power to determine whether or not a correlation existed between amount of damage and task performance.

\section{One-pair versus five-pair ODR performance}

As shown in Figure 7, all animals obtained similar scores in learning the two tasks $\left(F_{(1,10)}=0.16, p>0.05\right.$ and $F_{(1,10)}=0.26, p>$ 0.05 for trials and errors, respectively) and there were no group by task interactions. However, as predicted, all animals made more reversal errors in the five-pair ODR than the one-pair ODR 
$\left(F_{(1,10)}=28.62, p<0.001\right)$, but not more perseverative errors, and the interactions between group and task did not reach significance for any parameters. Similarly, for the stages of learning, only the effect of tasks was significant $\left(F_{(2,10)}=8.27, p<\right.$ $0.05 ; F_{(2,10)}=18.87, p<0.05$; and $F_{(2,10)}=$ 18.57, $p<0.05$, for stages I, II, and III, respectively).

In summary, selective lesions of OFC areas 11 and 13 resulted in a remarkable sparing of abilities to solve the ODR task even when the animals were given a more challenging ODR task, in which they had to concurrently learn and reverse five discrimination problems. In addition, the lack of ODR impairment after selective lesions of the amygdala confirms and extends the earlier findings from Izquierdo and Murray (2004). Thus, neither OFC areas 11 and 13 nor the amygdala seem critical for suppression of responses that are no longer rewarded.

\section{Discussion}

Selective damage to the amygdala spares ODR task performance

Monkeys with selective amygdala lesions were unimpaired in the one-pair ODR task, confirming recent findings (Izquierdo and Murray, 2004) and extending these findings by showing that the lack of impairment persisted even when the task required the animals to concurrently learn and reverse five discrimination problems. Thus, the lack of impairment after amygdalectomy does not seem to result from the ease of learning a simpler reversal task. Nevertheless, amygdala neurons have been shown to modulate their activity

based on shifts in reward contingency (Nishijo et al., 1988; Schultz, 2004; Paton et al., 2006; Salzman et al., 2007; Schoenbaum et al., 2007), suggesting an important role for the amygdala in computing and rapidly updating reward expectation. These two sets of findings do not necessarily conflict given that ODR performance is supported by a neural network that not only includes the amygdala but also the OFC areas and their connections with the medial temporal cortical areas and the striatum (Divac et al., 1967; Baxter and Murray, 2001; Clark et al., 2004; Budhani et al., 2007; Man et al., 2009). Thus, it is likely that other structures could allow nearly normal ODR performance in the absence of a functional amygdala. Future primate studies using reversible inactivation of the amygdala together with functional imaging could provide critical information on the interactions between the amygdala and other brain structures mediating reversal learning, as recently demonstrated in a neuroimaging study of two patients with amygdala damage (Hampton et al., 2007).

\section{Selective damage to areas 11 and 13 spares ODR task performance}

Damage restricted to OFC areas 11/13 alters neither the overall performance across the six reversals nor the learning patterns as measured by stages of learning. This lack of impairment persisted
A-ibo-5
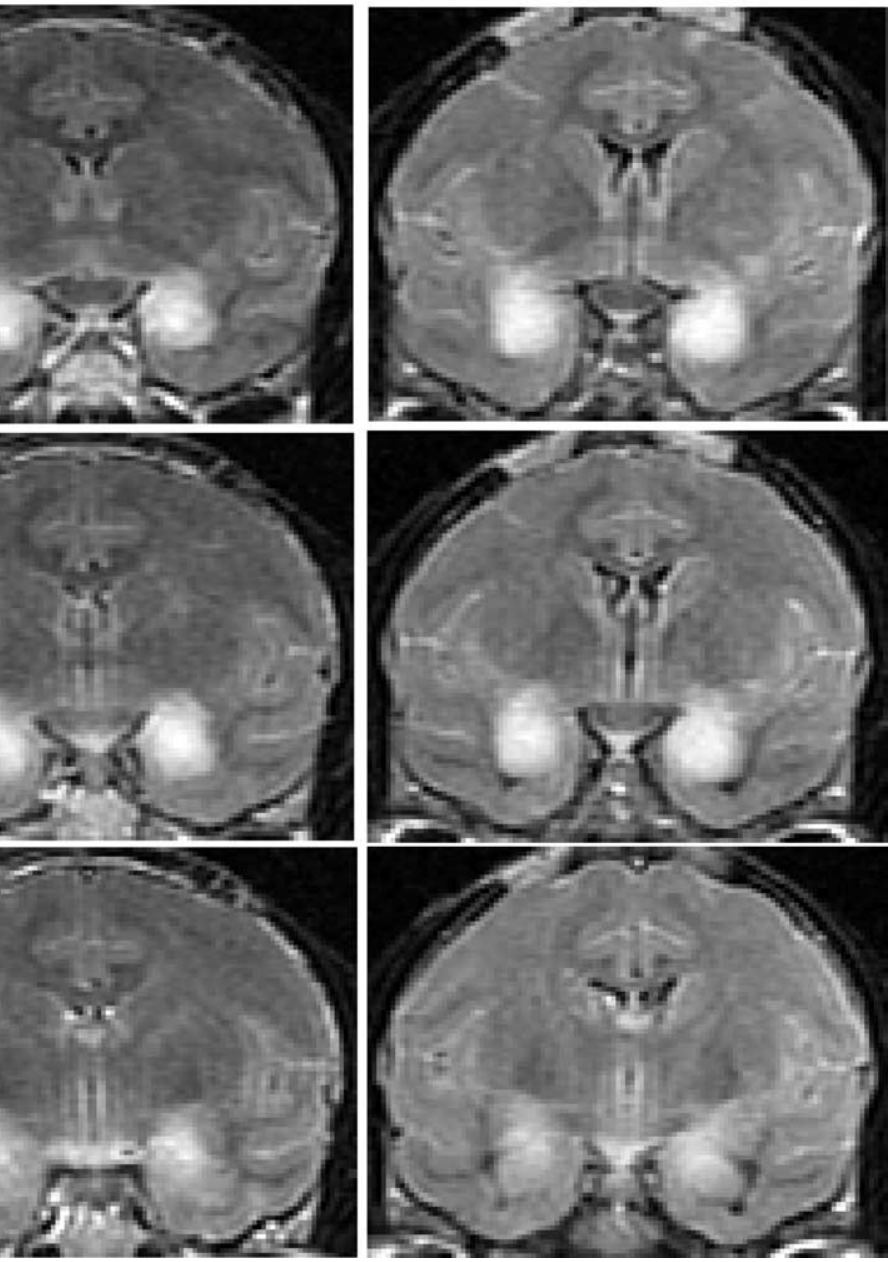

Figure 5. Coronal MR images through three anterior-posterior levels of the amygdala in two representative cases (A-ibo-5 and A-ibo-7). FLAIR images show areas of hypersignals (white blobs) indicative of edema resulting from neurotoxin-induced cell death. The numerals on the left indicate the distance in millimeters from the interaural plane.

even when task difficulty was increased to five discrimination problems. However, it is still possible that more challenging task manipulation, such as the use of unpredictable reward outcomes providing greater ambiguity, may be needed to engage areas $11 / 13$ as already shown in neuroimaging studies in humans (O’Doherty et al., 2001; Cools et al., 2002; O’Doherty et al., 2003).

This lack of impairment conflicts with previous reports in monkeys, but the differences cannot simply reflect procedural variations between studies. For example, a correction procedure was used in the present study to measure perseverative errors but not in the recent study of Izquierdo and Murray (2004). This correction procedure could have helped animals with OFC lesions to more rapidly learn that the reward contingency had changed. This possibility is unlikely, however, given that monkeys with OFC lesions in our earlier study (Meunier et al., 1997) were impaired on the ODR despite the use of a correction procedure. The major difference between this latter study and the present one is in the extent of the OFC lesion produced. In Meunier and colleagues (1997), the lesions included area 14 in addition to areas 11 and 13 as in the study by Izquierdo and Murray (2004). These data suggest either that the three OFC fields need to be damaged to yield the ODR deficit or that area 14 may play a more critical role in ODR learning than areas 11/13. 
A-ibo-8
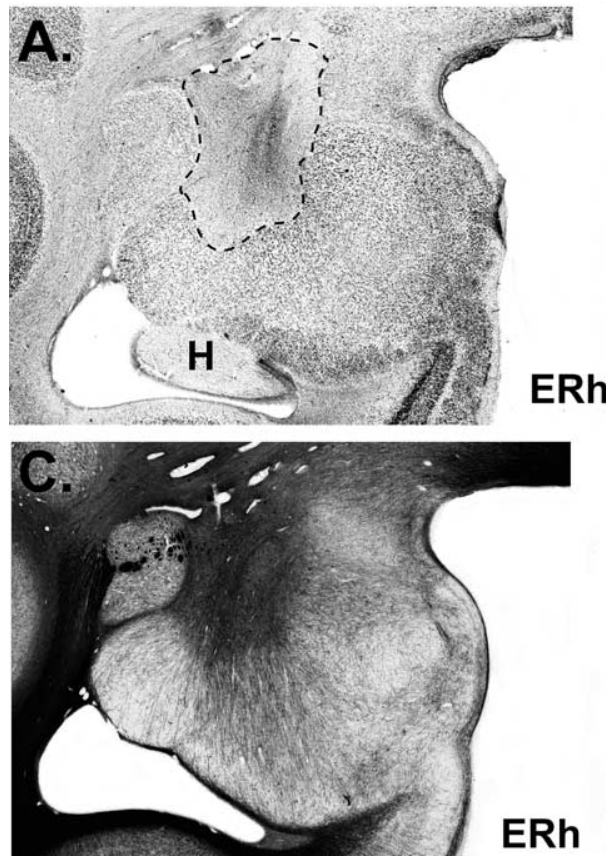

ERh

Figure 6. Histological coronal section through the amygdala of case A-ibo-8 that sustained the smallest lesion. $A$ and $\boldsymbol{B}$ display the extent of cell loss as revealed by thionin stain and highlighted with a dashed line. $\boldsymbol{C}$ and $\boldsymbol{D}$ display sparing of fibers (darker areas) as revealed by Gallyas stain in areas where cell loss was almost complete. ERh, Entorhinal cortex; H, hippocampus.

\section{Table 4. One-pair ODR task}

\begin{tabular}{|c|c|c|c|c|c|c|c|c|c|}
\hline & Acq & $\operatorname{Rev} 1$ & $\operatorname{Rev} 2$ & $\operatorname{Rev} 3$ & $\operatorname{Rev} 4$ & $\operatorname{Rev} 5$ & $\operatorname{Rev} 6$ & $\begin{array}{l}\text { Total } \\
\text { reversal } \\
\text { errors }\end{array}$ & $\begin{array}{l}\text { Total } \\
\text { perseverative } \\
\text { errors }\end{array}$ \\
\hline \multicolumn{10}{|l|}{ Group C } \\
\hline$(-2$ & 4 & 26 & 12 & 9 & 9 & 5 & 4 & 65 & 13 \\
\hline$(-3$ & 11 & 17 & 24 & 29 & 12 & 14 & 3 & 99 & 26 \\
\hline$(-7$ & 0 & 10 & 10 & 6 & 4 & 13 & 5 & 48 & 24 \\
\hline$(-9$ & 6 & 11 & 18 & 5 & 4 & 6 & 0 & 44 & 4 \\
\hline$C-10$ & 22 & 7 & 13 & 0 & 19 & 24 & 14 & 77 & 48 \\
\hline$C-11$ & 5 & 11 & 12 & 13 & 15 & 13 & 16 & 80 & 88 \\
\hline$x$ & 8 & 14 & 15 & 10 & 11 & 13 & 7 & 69 & 34 \\
\hline \multicolumn{10}{|l|}{ Group 0} \\
\hline 0-ibo-1 & 15 & 58 & 10 & 15 & 8 & 18 & 8 & 117 & 18 \\
\hline 0-ibo-2 & 7 & 14 & 15 & 12 & 7 & 9 & 8 & 65 & 34 \\
\hline 0 -asp-1 & 4 & 11 & 45 & 17 & 11 & 69 & 10 & 163 & 26 \\
\hline 0 -asp-2 & 35 & 35 & 15 & 14 & 13 & 7 & 39 & 123 & 11 \\
\hline 0 -asp-4 & 29 & 9 & 4 & 12 & 14 & 17 & 12 & 68 & 19 \\
\hline 0 -asp-5 & 5 & 6 & 11 & 22 & 21 & 10 & 25 & 95 & 110 \\
\hline 0 -asp-6 & 13 & 28 & 23 & 28 & 15 & 25 & 33 & 152 & 308 \\
\hline$x$ & 15 & 23 & 18 & 17 & 13 & 22 & 19 & 112 & 75 \\
\hline \multicolumn{10}{|l|}{ Group A-ibo } \\
\hline A-ibo-1 & 12 & 42 & 43 & 11 & 5 & 10 & 35 & 146 & 13 \\
\hline A-ibo-2 & 7 & 42 & 20 & 10 & 6 & 9 & 5 & 92 & 9 \\
\hline A-ibo-3 & 80 & 10 & 43 & 17 & 40 & 8 & 13 & 131 & 32 \\
\hline A-ibo-4 & 7 & 26 & 20 & 38 & 22 & 57 & 9 & 172 & 60 \\
\hline A-ibo-7 & 12 & 4 & 13 & 10 & 11 & 5 & 9 & 52 & 29 \\
\hline A-ibo-8 & 7 & 10 & 8 & 9 & 11 & 12 & 13 & 63 & 48 \\
\hline A-ibo-9 & 29 & 14 & 17 & 22 & 25 & 15 & 9 & 102 & 16 \\
\hline$x$ & 22 & 21 & 23 & 17 & 17 & 17 & 13 & 108 & 30 \\
\hline
\end{tabular}

Scores are total number of errors made before criterion days for the acquisition (Acq) and each of the six reversals (Rev 1 to $\operatorname{Rev} 6$ ) as well as total reversal errors and total perseverative errors across the six reversals. X, Group mean.

This latter interpretation is consistent with several other findings. First, our correlation analysis already pointed to a positive association between the amount of damage to area 14 and reversal errors. Second, Butter (1969) had demonstrated that ODR deficits did not occur after lesions restricted to either rostral OFC (e.g., 11 and 10) or caudal OFC (areas 13 and ia), but were severe following selective area 12 lesions. Third, in humans, changes in activity related to response suppression necessary for ODR performance are found in area 12 and/or ventromedial areas $(14,25$, and subgenual cortex) and less so in areas 11/13 (Bechara et al., 1999; Konishi et al., 1999; Elliott et al., 2000a; Fellows and Farah, 2003; Kringelbach and Rolls, 2003, 2004; Hurliman et al., 2005; Hampton et al., 2006, 2007; Budhani et al., 2007), and subgenual prefrontal regions are activated by negative feedback (Mars et al., 2005; van Duijvenvoorde et al., 2008; Zanolie et al., 2008). In addition, Kringelbach and Rolls (2004) have suggested that lateral OFC areas relate to punishers, whereas medial OFC areas relate to reward monitoring. Thus, given the anatomical connections between lateral area 12 and medial areas 14/25 (Barbas, 2007; Price, 2007), it is possible that, in the absence of areas 11/13, area 12 could still process the punishment associated with the object (no reward) and could pass this information directly to areas $14 / 25$, which have been implicated in the visceral control of emotional regulation. Finally, the lack of ODR impairment after orbital frontal areas 11/13 strengthened other recent findings indicating that damage to the orbital frontal cortex might not affect all tasks requiring behavioral inhibition (Chudasama et al., 2007; Schoenbaum et al., 2007; Gaffan and Wilson, 2008) [but for an alternative explanation, see also Man et al. (2009)].

Yet, the significant changes in neural activity found in the same OFC areas 11/13 when reward contingency of stimuli has changed (Thorpe et al., 1983; Rolls, 1996; O’Doherty et al., 2001; Kringelbach and Rolls, 2003; Wallis and Miller, 2003) is at odds with the lack of ODR impairment following damage to these same areas. Although the loss of coding incentive value after orbital frontal lesions has been used to explain the deficits found in both the ODR and Reinforcer tasks, this proposal is no longer tenable in light of the present results.

\section{Amygdala and OFC interactions and the processing of affective values}

Despite normal performance in the ODR, the same animals with amygdala and areas 11/13 lesions were unable to shift choices away from objects associated with a devalued food in a reinforcer devaluation task (Machado and Bachevalier, 2007a). Given that earlier reports have stressed the critical contribution of amygdala/OFC interactions to flexibly adjust choice selection based on reward value as well as on reward contingency (Málková et al., 1997; Baxter et al., 2000; Izquierdo and Murray, 2004, 2007; Izquierdo et al., 2004; Hampton et al., 2007; Schoenbaum et al., 2007), the present findings suggest that the interactions of the amygdala with areas $11 / 13$ are necessary to adjust choices based on reward value (relative value) but less so for choices based on reward contingency (absolute value). This latter function could perhaps involved interactions between the amygdala and orbital frontal fields other than areas 11/13 since the amygdala is interconnected with several orbital frontal fields including the most medial subgenual fields and the most lateral area 12 (Barbas, 
Table 5. Five-pair ODR task

\begin{tabular}{|c|c|c|c|c|c|c|c|c|c|}
\hline & Acq & Rev 1 & Rev 2 & $\operatorname{Rev} 3$ & Rev 4 & $\operatorname{Rev} 5$ & Rev 6 & $\begin{array}{l}\text { Total } \\
\text { reversal } \\
\text { errors }\end{array}$ & $\begin{array}{l}\text { Total } \\
\text { perseverative } \\
\text { errors }\end{array}$ \\
\hline \multicolumn{10}{|l|}{ Group C } \\
\hline$(-7$ & 0 & 34 & 77 & 57 & 27 & 57 & 39 & 291 & 16 \\
\hline$(-9$ & 0 & 14 & 30 & 21 & 10 & 18 & 15 & 108 & 2 \\
\hline$C-10$ & 4 & 33 & 14 & 72 & 21 & 27 & 27 & 194 & 162 \\
\hline$C-11$ & 30 & 39 & 66 & 79 & 55 & 59 & 63 & 361 & 33 \\
\hline$X$ & 9 & 30 & 47 & 57 & 28 & 40 & 36 & 239 & 53 \\
\hline \multicolumn{10}{|l|}{ Group 0} \\
\hline 0 -asp-4 & 0 & 51 & 46 & 53 & 0 & 34 & 24 & 208 & 3 \\
\hline 0 -asp-5 & 20 & 37 & 48 & 45 & 34 & 49 & 46 & 259 & 4 \\
\hline 0 -asp-6 & 10 & 44 & 26 & 28 & 38 & 49 & 63 & 248 & 28 \\
\hline X & 10 & 44 & 40 & 42 & 24 & 44 & 84 & 239 & 12 \\
\hline \multicolumn{10}{|l|}{ Group A } \\
\hline A-ibo-7 & 4 & 35 & 48 & 43 & 37 & 46 & 27 & 236 & 4 \\
\hline A-ibo-8 & 14 & 18 & 26 & 29 & 14 & 15 & 35 & 137 & 21 \\
\hline A-ibo-9 & 20 & 14 & 32 & 30 & 20 & 18 & 26 & 140 & 1 \\
\hline$X$ & 13 & 22 & 35 & 34 & 24 & 26 & 29 & 171 & 9 \\
\hline
\end{tabular}

Scores are total number of errors made before criterion days for the acquisition (Acq) and each of the six reversals (Rev 1 to Rev 6) as well as total reversal errors and total perseverative errors across the six reversals. $X$, Group mean.

1-Pair ODR

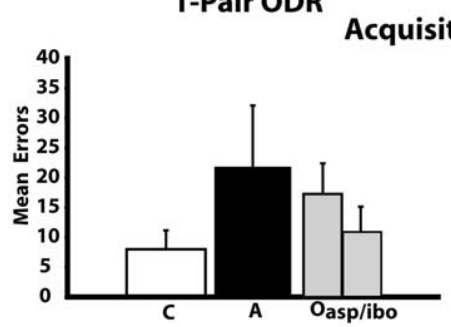

Reversals
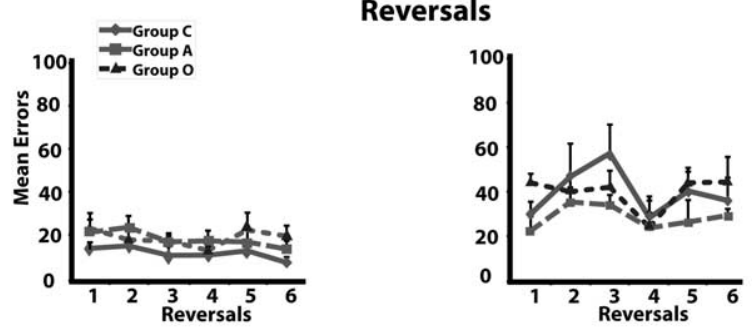

Stages of Learning
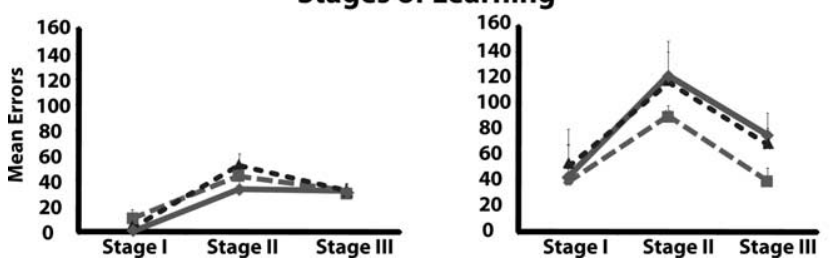

Figure 7. Mean errors made before criterion for the one-pair (left) and the five-pair (right) ODR tasks. The top graphs illustrate the mean number of errors made during acquisition of the discrimination problems. The middle graphs depict the mean number of reversal errors for each reversal. The bottom graphs represent the mean number of errors for each stage of learning as defined by Jones and Mishkin (1972) (see details in Materials and Methods, Data analysis). C, Animals with sham operations; A, animals with neurotoxic amygdala lesions; 0-asp or 0-ibo, animals with aspiration or ibotenic acid lesion of areas 11 and 13; 0 , groups 0 -asp and 0 -ibo combined.

2007; Ghashghaei et al., 2007). Future studies are clearly required to better identify the specific interactive processes by which different OFC fields and the amygdala may support performance on ODR and reinforcer devaluation tasks. In this regard, unilateral disconnection studies (Baxter et al., 2000; Gaffan and Wilson, 2008) may be fruitful in disentangling the neural substrate underlying these different processes.

It is interesting to note that the reinforcer devaluation deficit after damage to the amygdala and areas 11/13 was also associated with difficulty in modulating emotional reactivity when the same animals were challenged with social stimuli differing in the magnitude of threat as assessed by the human intruder task (Machado and Bachevalier, 2007b). In this task, the animals are alone in a room into which an unfamiliar human entered, presenting either his/her profile to the animals (low intensity threat) or staring directly at the animals (high intensity threat). Before surgery, all animals showed higher frequency of tension-related behaviors in the staring condition than in the profile condition, indicating that they could modulate their emotional responses according to the intensity of threat provided by the intruder. After surgery, however, only sham-operated control animals continued to demonstrate this ability. Animals with amygdala and OFC lesions displayed higher, but similar, levels of tension-related behaviors to both conditions compared with their presurgical scores. Thus, as for the reinforcer devaluation task, both amygdala and ORB areas $11 / 13$ seem critical to flexibly adjust emotional reactivity based on the magnitude of negative signals, such as threat.

The impairment in monitoring the positive and negative value of social cues after amygdala and OFC areas 11/13 lesions could also be the source of the striking behavioral changes found in the same animals when placed in small familiar social groups (Machado and Bachevalier, 2006). In this latter study, we reported that animals with amygdala lesions displayed several personality changes that preclude positive social interactions (increased exploration and excitability; decreased affiliation and popularity) and made abnormal responses to threatening social signals. In contrast, animals with orbital frontal lesions were involved in more aggressive interactions and responded abnormally to both affiliative and threatening signals. All together the data demonstrate that flexible decision-making mechanisms mediated by the amygdala and OFC areas 11/13 are critical to support normal social behavior. However, because these data were collected on animals that had been raised in large social groups but were singly housed at the time of these experiments, they will need to be confirmed by studies on animals maintained in a more naturalistic environment.

\section{References}

Amaral DG, Price JL, Pitkanen A, Carmichael ST (1992) Anatomical organization of the primate amygdaloid complex. In: The amygdala: neurobiological aspects of emotion, memory and mental dysfunction (Aggleton, JP, ed), pp 1-65: New York: Wiley.

Barbas H (2007) Flow of information for emotions through temporal and orbitofrontal pathways. J Anat 211:237-249.

Barbas H, Pandya DN (1989) Architecture and intrinsic connections of the prefrontal cortex in the rhesus monkey. J Comp Neurol 286:353-375.

Barbas H, Medalla M, Alade O, Suski J, Zikopoulos B, Lera P (2005) Relationship of prefrontal connections to inhibitory systems in superior temporal areas in the rhesus monkey. Cereb Cortex 15:1356-1370.

Baxter MG, Murray EA (2001) Impairments in visual discrimination learn- 
ing and recognition memory produced by neurotoxic lesions of rhinal cortex in rhesus monkeys. Eur J Neurosci 13:1228-1238.

Baxter MG, Parker A, Lindner CC, Izquierdo AD, Murray EA (2000) Control of response selection by reinforcer value requires interaction of amygdala and orbital prefrontal cortex. J Neurosci 20:4311-4319.

Bechara A, Damasio H, Tranel D, Damasio AR (1997) Deciding advantageously before knowing the advantageous strategy. Science 275:1293-1295.

Bechara A, Damasio H, Damasio AR, Lee GP (1999) Different contributions of the human amygdala and ventromedial prefrontal cortex to decisionmaking. J Neurosci 19:5473-5481.

Bohn I, Giertler C, Hauber W (2003) Orbital prefrontal cortex and guidance of instrumental behaviour in rats under reversal conditions. Behav Brain Res 143:49-56.

Budhani S, Marsh AA, Pine DS, Blair RJ (2007) Neural correlates of response reversal: considering acquisition. Neuroimage 34:1754-1765.

Butter CM (1969) Perseveration in extinction and in discrimination reversal tasks following selective frontal ablations in Macaca mulatta. Physiol Behav 4:163-171.

Carmichael ST, Price JL (1994) Architectonic subdivision of the orbital and medial prefrontal cortex in the macaque monkey. J Comp Neurol 346:366-402.

Chudasama Y, Robbins TW (2003) Dissociable contributions of the orbitofrontal and infralimbic cortex to pavlovian autoshaping and discrimination reversal learning: further evidence for the functional heterogeneity of the rodent frontal cortex. J Neurosci 23:8771-8780.

Chudasama Y, Kralik JD, Murray EA (2007) Rhesus monkeys with orbital prefrontal cortex lesions can learn to inhibit prepotent responses in the reversed reward contingency task. Cereb Cortex 17:1154-1159.

Clark L, Cools R, Robbins TW (2004) The neuropsychology of ventral prefrontal cortex: decision-making and reversal learning. Brain Cogn 55:41-53.

Cools R, Clark L, Owen AM, Robbins TW (2002) Defining the neural mechanisms of probabilistic reversal learning using event-related functional magnetic resonance imaging. J Neurosci 22:4563-4567.

Dias R, Robbins TW, Roberts AC (1996) Dissociation in prefrontal cortex of affective and attentional shifts. Nature 380:69-72.

Divac I, Rosvold HE, Szwarcbart MK (1967) Behavioral effects of selective ablation of the caudate nucleus. J Comp Physiol Psychol 63:184-190.

Elliott R, Dolan RJ, Frith CD (2000a) Dissociable functions in the medial and lateral orbitofrontal cortex: evidence from human neuroimaging studies. Cereb Cortex 10:308-317.

Elliott R, Friston KJ, Dolan RJ (2000b) Dissociable neural responses in human reward systems. J Neurosci 20:6159-6165.

Fellows LK, Farah MJ (2003) Ventromedial frontal cortex mediates affective shifting in humans: evidence from a reversal learning paradigm. Brain 126:1830-1837.

Ferry AT, Lu XC, Price JL (2000) Effects of excitotoxic lesions in the ventral striatopallidal-thalamocortical pathway on odor reversal learning: inability to extinguish an incorrect response. Exp Brain Res 131:320-335.

Gaffan D, Wilson CRE (2008) Medial temporal and prefrontal function: recent behavioural disconnection studies in the macaque monkey. Cortex 44:928-935.

Gallyas F (1979) Silver staining of myelin by means of physical development. Neurol Res 1:203-209.

Gellerman LW (1933) Chance orders of visual stimuli in visual discrimination experiments. J Genet Psychol 42:206-208.

Ghashghaei HT, Hilgetag CC, Barbas H (2007) Sequence of information processing for emotions based on the anatomic dialogue between prefrontal cortex and amygdala. Neuroimage 34:905-923.

Gundersen HJ, Jensen EB (1987) The efficiency of systematic sampling in stereology and its prediction. J Microsc 147:229-263.

Hampton AN, Bossaerts P, O'Doherty JP (2006) The role of the ventromedial prefrontal cortex in abstract state-based inference during decision making in humans. J Neurosci 26:8360-8367.

Hampton AN, Adolphs R, Tyszka MJ, O’Doherty JP (2007) Contributions of the amygdala to reward expectancy and choice signals in human prefrontal cortex. Neuron 55:545-555.

Hodos W, Bobko P (1984) A weighted index of bilateral brain lesions. J Neurosci Methods 12:43-47.

Hornak J, O’Doherty J, Bramham J, Rolls ET, Morris RG, Bullock PR, Polkey CE (2004) Reward-related reversal learning after surgical excisions in orbito-frontal or dorsolateral prefrontal cortex in humans. J Cogn Neurosci 16:463-478.

Hurliman E, Nagode JC, Pardo JV (2005) Double dissociation of exteroceptive and interoceptive feedback systems in the orbital and ventromedial prefrontal cortex of humans. J Neurosci 25:4641-4648.

Iversen SD, Mishkin M (1970) Perseverative interference in monkeys following selective lesions of the inferior prefrontal convexity. Exp Brain Res 11:376-386.

Izquierdo A, Murray EA (2004) Combined unilateral lesions of the amygdala and orbital prefrontal cortex impair affective processing in rhesus monkeys. J Neurophysiol 91:2023-2039.

Izquierdo A, Murray EA (2007) Selective bilateral amygdala lesions in rhesus monkeys fail to disrupt object reversal learning. J Neurosci 27:1054-1062.

Izquierdo A, Suda RK, Murray EA (2004) Bilateral orbital prefrontal cortex lesions in rhesus monkeys disrupt choices guided by both reward value and reward contingency. J Neurosci 24:7540-7548.

Jones B, Mishkin M (1972) Limbic lesions and the problem of stimulusreinforcement associations. Exp Neurol 36:362-377.

Kim J, Ragozzino ME (2005) The involvement of the orbitofrontal cortex in learning under changing task contingencies. Neurobiol Learn Mem 83:125-133.

Konishi S, Kawazu M, Uchida I, Kikyo H, Asakura I, Miyashita Y (1999) Contribution of working memory to transient activation in human inferior prefrontal cortex during performance of the Wisconsin Card Sorting Test. Cereb Cortex 9:745-753.

Kringelbach ML, Rolls ET (2003) Neural correlates of rapid reversal learning in a simple model of human social interaction. Neuroimage 20:1371-1383.

Kringelbach ML, Rolls ET (2004) The functional neuroanatomy of the human orbitofrontal cortex: evidence from neuroimaging and neuropsychology. Prog Neurobiol 72:341-372.

Machado CJ, Bachevalier J (2006) The impact of selective amygdala, orbital frontal cortex, or hippocampal formation lesions on established social relationships in rhesus monkeys (Macaca mulatta). Behav Neurosci 120:761-786

Machado CJ, Bachevalier J (2007a) The effects of selective amygdala, orbital frontal cortex or hippocampal formation lesions on reward assessment in nonhuman primates. Eur J Neurosci 25:2885-2904.

Machado CJ, Bachevalier J (2007b) Measuring reward assessment in a seminaturalistic context: the effects of selective amygdala, orbital frontal or hippocampal lesions. Neuroscience 148:599-611.

Machado CJ, Bachevalier J (2008) Behavioral and hormonal reactivity to threat: effects of selective amygdala, hippocampal or orbital frontal lesions in monkeys. Psychoneuroendocrinology 33:926-941.

Málková L, Gaffan D, Murray EA (1997) Excitotoxic lesions of the amygdala fail to produce impairment in visual learning for auditory secondary reinforcement but interfere with reinforcer devaluation effects in rhesus monkeys. J Neurosci 17:6011-6020.

Málková L, Lex CK, Mishkin M, Saunders RC (2001) MRI-based evaluation of locus and extent of neurotoxic lesions in monkeys. Hippocampus 11:361-370.

Man MS, Clarke HF, Roberts AC (2009) The role of the orbitofrontal cortex and medial striatum in the regulation of prepotent responses to food rewards. Cereb Cortex. Advance online publication. Retrieved February 2, 2009. doi:10.1093/cercor/bhn137.

Mars RB, Coles MG, Grol MJ, Holroyd CB, Nieuwenhuis S, Hulstijn W, Toni I (2005) Neural dynamics of error processing in medial frontal cortex. Neuroimage 28:1007-1013.

McAlonan K, Brown VJ (2003) Orbital prefrontal cortex mediates reversal learning and not attentional set shifting in the rat. Behav Brain Res 146:97-103.

Meunier M, Bachevalier J, Mishkin M (1997) Effects of orbital frontal and anterior cingulate lesions on object and spatial memory in rhesus monkeys. Neuropsychologia 35:999-1015.

Nemanic S, Alvarado MC, Price RE, Jackson EF, Bachevalier J (2002) Assessment of locus and extent of neurotoxic lesions in monkeys using neuroimaging techniques: a replication. J Neurosci Methods 121:199-209.

Nemanic S, Alvarado MC, Bachevalier J (2004) The hippocampal/parahippocampal regions and recognition memory: insights from visual paired 
comparison versus object-delayed nonmatching in monkeys. J Neurosci 24:2013-2026.

Nishijo H, Ono T, Nishino H (1988) Single neuron responses in amygdala of alert monkey during complex sensory stimulation with affective significance. J Neurosci 8:3570-3583.

O’Doherty J, Kringelbach ML, Rolls ET, Hornak J, Andrews C (2001) Abstract reward and punishment representations in the human orbitofrontal cortex. Nat Neurosci 4:95-102.

O’Doherty J, Critchley H, Deichmann R, Dolan RJ (2003) Dissociating valence of outcome from behavioral control in human orbital and ventral prefrontal cortices. J Neurosci 23:7931-7939.

Paton JJ, Belova MA, Morrison SE, Salzman CD (2006) The primate amygdala represents the positive and negative value of visual stimuli during learning. Nature 439:865-870.

Petrides M, Pandya DN (1984) Projections to the frontal cortex from the posterior parietal region in the rhesus monkey. J Comp Neurol 228:105-116.

Price JL (2007) Definition of the orbital cortex in relation to specific connections with limbic and visceral structures and other cortical regions. Ann N Y Acad Sci 1121:54-71.

Price JL, Carmichael ST, Drevets WC (1996) Networks related to the orbital and medial prefrontal cortex; a substrate for emotional behavior? Prog Brain Res 107:523-536.

Roberts AC (2006) Primate orbitofrontal cortex and adaptive behaviour. Trends Cogn Sci 10:83-90.

Rolls ET (1996) The orbitofrontal cortex. Philos Trans R Soc Lond B Biol Sci 351:1433-1443.

Rolls ET, Hornak J, Wade D, McGrath J (1994) Emotion-related learning in patients with social and emotional changes associated with frontal lobe damage. J Neurol Neurosurg Psychiatry 57:1518-1524.

Salzman CD, Paton JJ, Belova MA, Morrison SE (2007) Flexible neural representations of value in the primate brain. Ann NY Acad Sci 1121:336-354.

Saunders RC, Aigner TG, Frank JA (1990) Magnetic resonance imaging of the rhesus monkey brain: use for stereotactic neurosurgery. Exp Brain Res 81:443-446.

Schoenbaum G, Nugent SL, Saddoris MP, Setlow B (2002) Orbitofrontal lesions in rats impair reversal but not acquisition of go, no-go odor discriminations. Neuroreport 13:885-890.

Schoenbaum G, Setlow B, Nugent SL, Saddoris MP, Gallagher M (2003) Lesions of orbitofrontal cortex and basolateral amygdala complex disrupt acquisition of odor-guided discriminations and reversals. Learn Mem 10:129-140.

Schoenbaum G, Saddoris MP, Stalnaker TA (2007) Reconciling the roles of orbitofrontal cortex in reversal learning and the encoding of outcome expectancies. Ann N Y Acad Sci 1121:320-335.

Schultz W (2004) Neural coding of basic reward terms of animal learning theory, game theory, microeconomics and behavioural ecology. Curr Opin Neurobiol 14:139-147.

Teitelbaum H (1964) A comparison of effects of orbitofrontal and hippocampal lesions upon discrimination learning and reversal in the cat Exp Neurol 9:452-462.

Thorpe SJ, Rolls ET, Maddison S (1983) The orbitofrontal cortex: neuronal activity in the behaving monkey. Exp Brain Res 49:93-115.

van Duijvenvoorde AC, Zanolie K, Rombouts SA, Raijmakers ME, Crone EA (2008) Evaluating the negative or valuing the positive? Neural mechanisms supporting feedback-based learning across development. J Neurosci 28:9495-9503.

Wallis JD (2007) Orbitofrontal cortex and its contribution to decisionmaking. Annu Rev Neurosci 30:31-56.

Wallis JD, Miller EK (2003) Neuronal activity in primate dorsolateral and orbital prefrontal cortex during performance of a reward preference task. Eur J Neurosci 18:2069-2081.

Zanolie K, Teng S, Donohue SE, van Duijvenvoorde AC, Band GP, Rombouts SA, Crone EA (2008) Switching between colors and shapes on the basis of positive and negative feedback: an fMRI and EEG study on feedbackbased learning. Cortex 44:537-547. 